\title{
CASE FOR DIAGNOSIS
}

\section{An asymptomatic male with mediastinal masses}

\author{
K-A. Wu*, W-C. Perng" ${ }^{\#}$, S-C. Lee ${ }^{\star}$, M-F. Cheng ${ }^{+}$, L-F. Sheu ${ }^{+}$and C-P. Wu ${ }^{\#}$
}

\section{CASE HISTORY}

A 35-yr-old obese male was admitted to the Tri-Service General Hospital (Taipei, Taiwan) for further examination of an abnormal opacity seen on a chest radiograph obtained during a medical check-up. The patient had been asymptomatic and had never received any treatment with steroids. Physical examination was unremarkable. Laboratory data, including complete blood count and tumour markers, were within normal limits. Abnormal laboratory findings from serological test were as follows: cholesterol $225 \mathrm{mg} \cdot \mathrm{dL}^{-1}$; aspartate aminotransferase $45 \mathrm{IU} \cdot \mathrm{L}^{-1}$; and alanine aminotransferase $61 \mathrm{IU} \cdot \mathrm{L}^{-1}$. The initial chest radiograph and computed tomography (CT) scan are seen in figures 1 and 2, respectively.
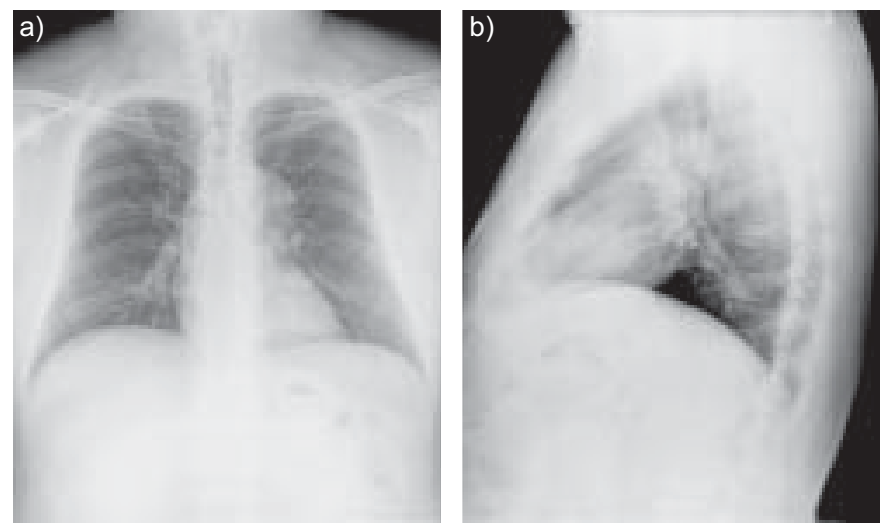

FIGURE 1. a) Posteroanterior and b) lateral chest radiographs at initial presentation.
The patient underwent mass resection via sternotomy. An oversized tumoural thymus (the first specimen) was resected in toto. However, the resected tumour was not comparable in size to the lesion discovered on CT imaging. A decision was made to incise the mediastinal pleura for confirmation of the pre-operative CT findings. A sizeable, whitish soft mass (the second specimen) was uncovered in the mediastinum, adjacent to the aortic arch. No attachment was found between the tumour and either the bronchial tree or oesophagus. Surgical excision of the tumour was performed. The histological findings of both specimens are shown in figures 3 and 4 .

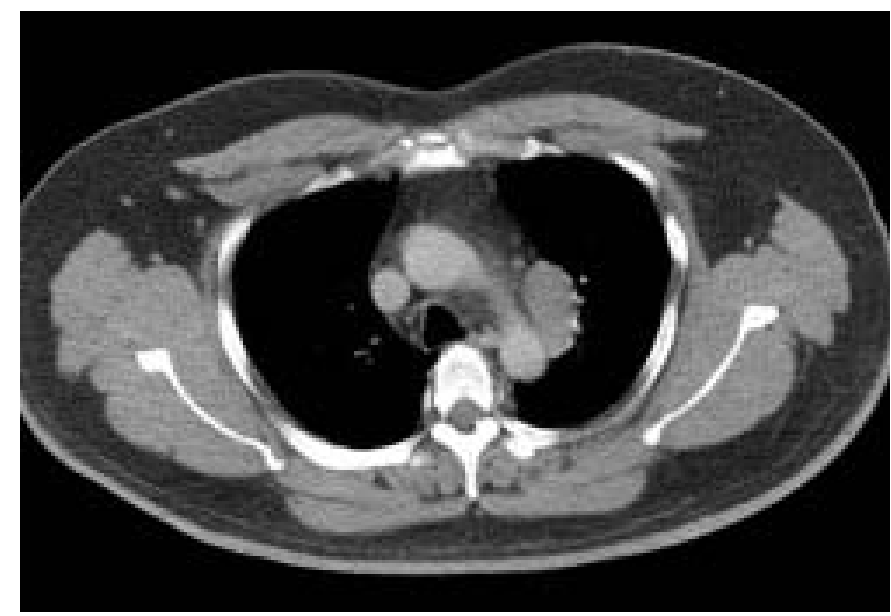

FIGURE 2. Contrast-enhanced computed tomography chest scan cut (mediastinal window) at initial presentation.

\footnotetext{
*Dept of Medicine, Tao-Yuan Armed Forces General Hospital, Taoyuan, and "Division of Thoracic Surgery, Dept of Surgery, ${ }^{+}$Dept of Pathology, and ${ }^{\#}$ Division of Pulmonary Medicine, Dept of Medicine, Tri-Service General Hospital, Taipei, Taiwan.

CORRESPONDENCE: C-P. Wu, Division of Pulmonary Medicine, Dept of Medicine, Tri-Service General Hospital, No. 325, Section 2, Cheng-Kung Road, Nei-Hu, Taipei, Taiwan. Fax: 886287927233. E-mail: chest@mail.ndmctsgh.edu.tw
} 

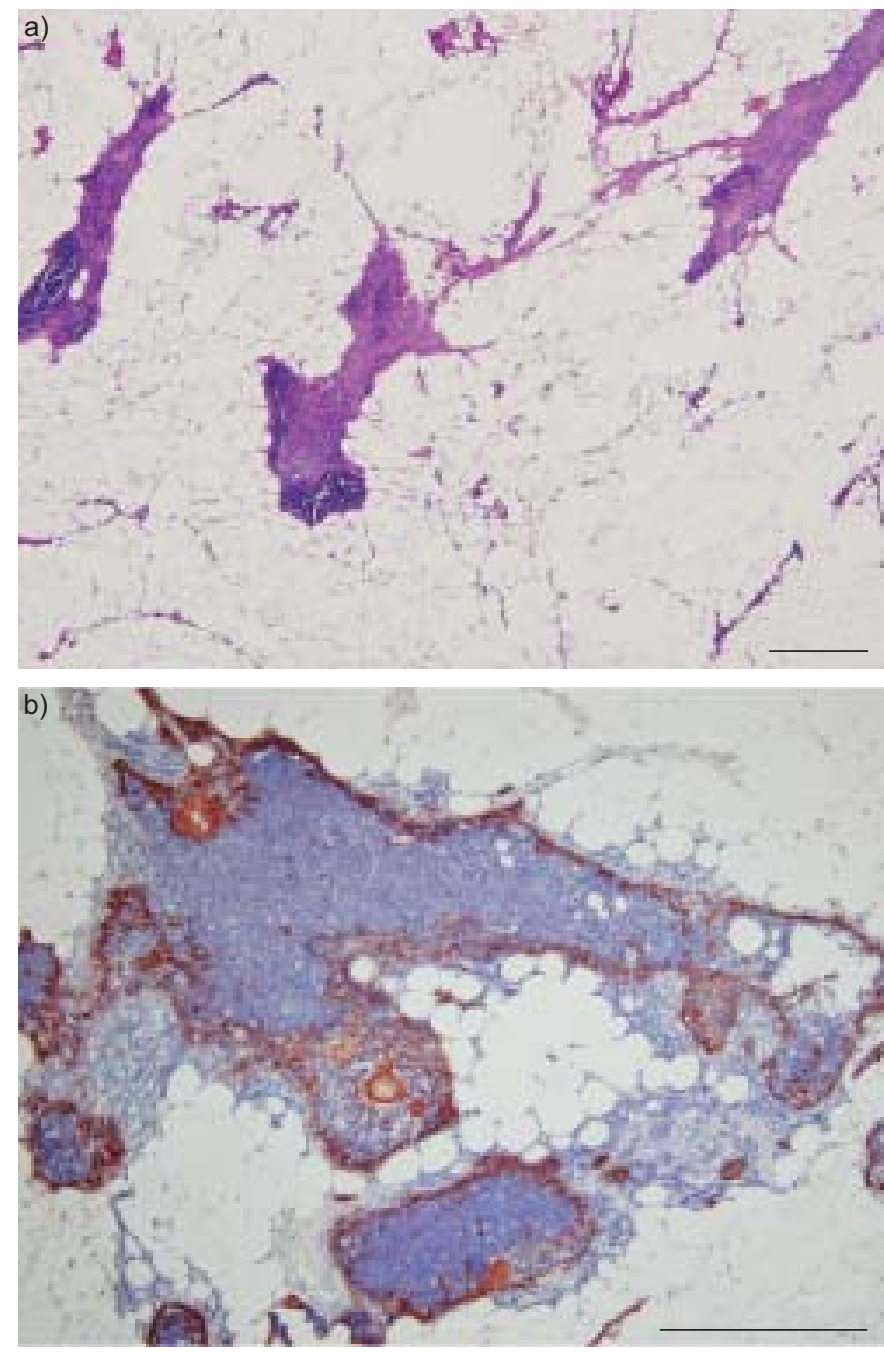

FIGURE 3. Representative microphotographs of the resected thymic tumour (the first specimen) using a) haematoxylin-eosin staining and b) AE 1/3 (pancytokeratin) immunohistochemical staining. Scale bars $=100 \mu \mathrm{m}(\mathrm{a})$ and $50 \mu \mathrm{m}$ (b)
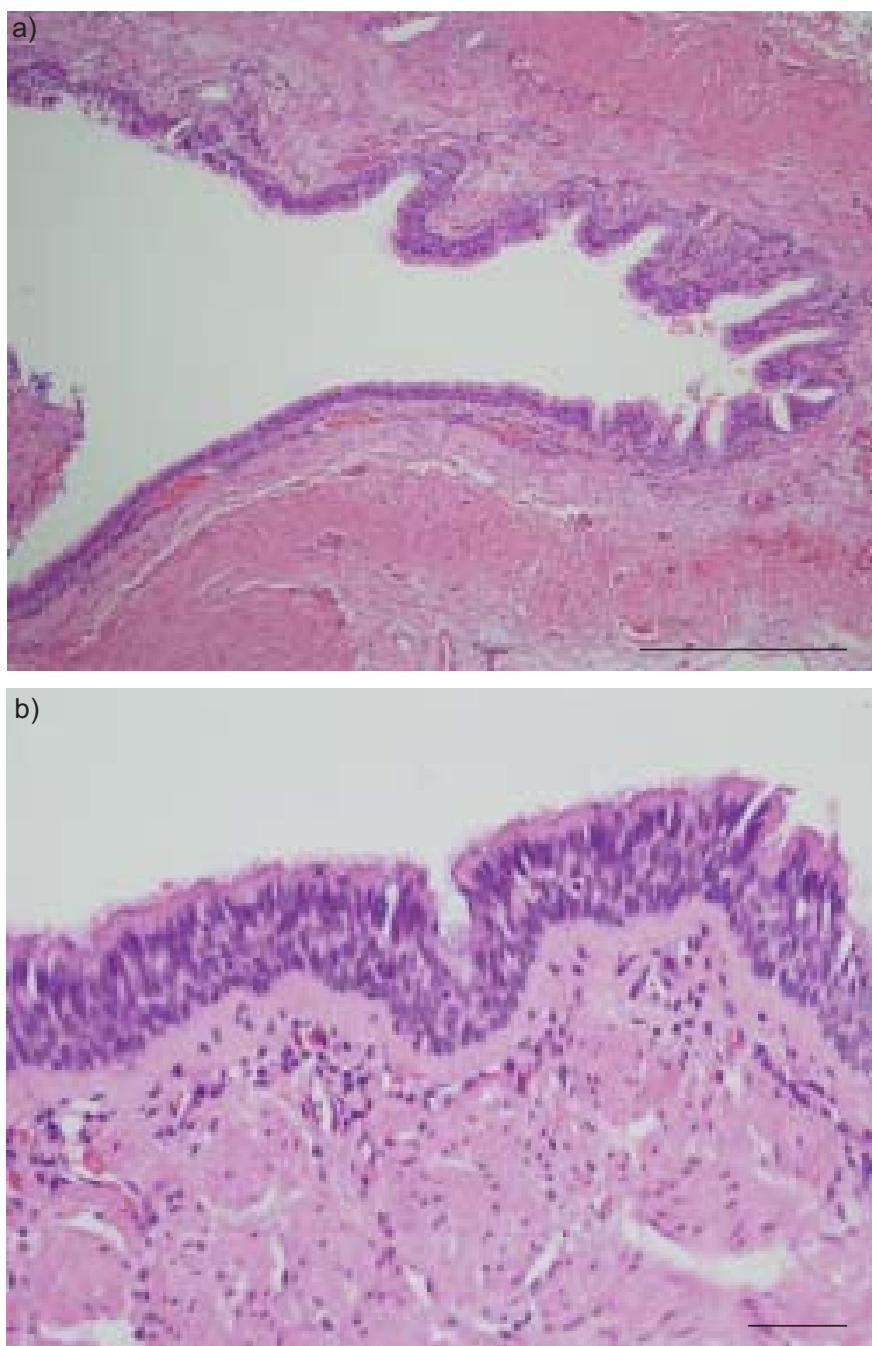

FIGURE 4. Representative microphotographs of the resected cystic mass (the second specimen) using haematoxylin-eosin staining ( $a$ and $b$ ). Scale bars $=50 \mu \mathrm{m}$ (a) and $10 \mu \mathrm{m}(\mathrm{b})$.

BEFORE TURNING THE PAGE, INTERPRET THE PATIENT'S HISTORY, CHEST RADIOGRAPH, COMPUTED TOMOGRAPHY SCAN AND MICROPHOTOGRAPHS, AND SUGGEST A DIAGNOSIS. 


\section{INTERPRETATION}

\section{Chest radiograph}

The initial chest radiograph (fig. 1) revealed a mass lesion superimposed on the aortic arch.

\section{Computed tomography scan}

On unenhanced CT scan, the mass appeared well circumscribed, oval and had a soft-tissue attenuation of about 35$60 \mathrm{HU}$. It was located in the left anterior mediastinal compartment and was adjacent to both the aortic arch and the thymus. After injection of contrast media (fig. 2), the mass itself was not enhanced.

\section{Histopathological picture}

In the pathological study of the resected thymic tumour (the first specimen), its gross features were soft in consistency and grey-yellow in colour. The tumour measured $8 \times 5 \times 1.5 \mathrm{~cm}$ in size and weighed $64.2 \mathrm{~g}$. The histopathological examination (fig. 3) revealed that the tumour consisted mainly of mature adipose tissue interspersed with islands of non-neoplastic thymic tissue containing Hassall's corpuscles, which had immunoreactivity for AE 1/3 (pan-cytokeratin).

The gross features of the second specimen were an ovoid shape, soft consistency and grey colour. The tumour was found to be filled with viscous, jelly-like fluid after dissection. On histopathological evaluation (fig. 4), it was found to be a cystic tumour with pseudo-stratified ciliated columnar epithelial lining.

\section{Diagnosis: Thymolipoma with a coexisting mediastinal foregut cyst.}

\section{CLINICAL COURSE}

During 6 months of follow-up, clinical evaluation and interval chest radiography were all stable. A repeat CT scan of the chest did not show any sign of recurrence. The patient continues to be well to the present day.

\section{DISCUSSION}

Foregut cysts are congenital lesions resulting from aberrant development of the primitive foregut, which originate from the endoderm [1, 2], between weeks $4-8$ of gestation [2]. Radiograph and CT scan characteristics of foregut cysts are well defined. On chest radiography, they appear as spherical, wellcircumscribed, homogeneous masses [1]. On CT scans, foregut cysts manifest as spherical masses of either water or soft-tissue attenuation [1, 3, 4]. The masses, with the exception of the capsule, do not show contrast enhancement after injection of contrast media [3]. When foregut cysts reveal soft-tissue attenuation masses on CT scans, differentiation from solid lesions can be more problematic. Magnetic resonance imaging can be useful for suggesting the true cystic nature of the lesion [3]. Foregut cysts are most often located in the hilum or middle mediastinum [5]. In the present case, the foregut cyst appeared to be of soft-tissue attenuation and located in the anterior mediastinum. Such uncommon characteristics on a CT scan suggested the diagnosis of thymic lesion in the first place.

Thymolipoma are rare tumours consisting of mature adipose tissue with interspersed islands of non-neoplastic thymic tissue [6]. Patients with thymolipomas may remain asymptomatic for a long period. The majority of cases are incidental findings on routine chest radiography or at autopsy [7]. On CT scans, thymolipomas demonstrate a mixture of fat and soft-tissue attenuation [8].

According to previous studies, thymic primordial appear late in the sixth week of gestation and originate from the endoderm $[9,10]$. The mean weight of a normal thymus is no larger than 30-40 g until puberty. A gradual process of involution then occurs throughout adulthood, and the weight of the thymus is reduced to $5-25 \mathrm{~g}$ [10]. At surgery, the present patient's sizeable tumoural thymus was resected. The pathological morphology supported the diagnosis of thymolipoma, which weighed $64.2 \mathrm{~g}$. To the present authors' knowledge, this case presents the second smallest thymolipoma documented in the literature (the smallest was $63 \mathrm{~g}$ [11]). The pathogenesis of thymolipoma is unclear and has been the subject of much speculation. Up to now, four theories have been proposed, but none has been solidly proved [12].

What is most interesting about the present case is that abnormal embryogenesis is the cause of the foregut cyst, and/or thymolipoma. Embryologically, both the foregut and the thymus have the common origin of the endoderm $[2,9]$. In the development of embryogenesis, foregut cysts appear between weeks 4 and 8 of gestation [2]. Simultaneously, the thymic primordia also appears in the sixth week of gestation as ventral outgrowths of the third pharyngeal pouches [10]. According to the similarity of embryological origins in both foregut cyst and thymus, as well as the similar period of gestation, the present authors suspect that the defects in endoderm during the common period may cause foregut cyst, and/ or thymic anomalies, including the potential cause of thymolipoma. The present case is one example of such a theory.

To the present authors' knowledge, foregut cysts in association with thymolipoma have not previously been described in the literature. The case presented here is particularly interesting because it is the first reported case of a foregut cyst coexisting with thymolipoma. Thus, the authors have coined the term "foregut-thymic anomaly" to represent such cases.

Due to the asymptomatic characteristic of thymolipoma, its disclosure is uncommon. The present authors believe that many more cases exist that embody their theory.

\section{REFERENCES}

1 Strollo DC, Rosado-de-Christenson ML, Jett JR. Primary mediastinal tumors: part II. Tumors of the middle and posterior mediastinum. Chest 1997; 112: 1344-1357.

2 Organogenetic period: fourth to eigth weeks. In: Moore KL, Persaud TVN. The Developing Human: Clinically Oriented Embryology. 7th Edn. Philadelphia, Saunders, 2003; pp. 77-80.

3 Jeung MY, Gasser B, Gangi A, et al. Imaging of cystic masses of the mediastinum. Radiographics 2002; 22: S79-S93.

4 Fitch SJ, Tonkin IL, Tonkin AK. Imaging of foregut duplication cysts. Radiographics 1986; 6: 189-201.

5 Kobzik L. The lung. In: Kumar V, Abbas AK, Fausto N. Robbins and Cotran Pathologic Basis of Disease. 7th Edn. Philadelphia, Saunders, 2003; p. 713. 
6 Marx A, Kuo TT, Ströbel Ph, Zhang PJ, Shimosato Y, Chan JKC. Soft tissue tumours of the thymus and mediastinum. In: Travis WD, Brambilla E, MullerHermelink HK, Harris CC. World Health Organization Classification of Tumours. Pathology and Genetics of Tumours of the Lung, Pleura, Thymus and Heart. Lyon, IARC Press, 2004; p. 239.

7 Peake JB, Zeigler MG. Thymolipoma: report of three cases. Am Surg 1977; 43: 477-479.

8 Rosado-de-Christenson ML, Pugatch RD, Moran CA, Galobardes J. Thymolipoma: analysis of 27 cases. Radiology 1994; 193: 121-126.
9 Introduction. In: Snell RS. Clinical Anatomy. 7th Edn. Philadelphia, Lippincott Williams \& Wilkins, 2004; p. 40.

10 Shields TW. The thymus. In: Shields TW, Locicero J 3rd, Ponn RB, Rusch VW. General Thoracic Surgery. 6th Edn. Philadelphia, Lippincott Williams \& Wilkins, 2005; pp. 2347-2349.

11 Scully NM. Lipothymoma with cystic lymphangioma: case report. Am Surg 1960; 26: 400-404.

12 Toyama T, Mizuno T, Masaoka A, et al. Pathogenesis of thymolipoma: report of three cases. Surg Today 1995; 25: 86-88. 